\title{
Para uma definição de Didática da História
}

Towards a History didactics definition

Oldimar Cardoso*

\section{RESUMO}

Este artigo visa definir a Didática da História de acordo com a atual bibliografia alemã, que a considera mais próxima da História do que da Educação. Associada à palavra Geschichtsdidaktik, essa definição se opõe aos conceitos de Didática da História como a arte de ensinar - Lehrkunst - História ou como uma coleção de métodos utilizáveis tanto no ensino de História quanto no de outras disciplinas escolares - Unterrichtsmethoden. Em oposição a essas duas definições, este artigo dialoga com as bibliografias alemã, francesa e brasileira para propor uma concepção de Didática da História como uma subárea da História, uma vez que ela não trata apenas da História escolar, mas de todas as elaborações da História sem forma científica - nichtwissenschaftsförmigen Geschichtsverarbeitungen.

Palavras-chave: Didática da História; metodologia de pesquisa didático-histórica; ensino de História.

\section{ABSTRACT}

This paper aims to define history didactics along the lines of the current German literature, which conceives it to be closer to history than to education. Associated to the word Geschichtsdidaktik, this definition is opposed to the concepts of history didactics as the art of teaching Lehrkunst - history or as a collection of methods used both in the teaching of history and in the teaching of other school subjects - Unterrichtsmethoden. In opposition to these two definitions, this paper discusses German, French and Brazilian literatures to propose a conception of history didactics as a subarea of history, once it does not encompass only history teaching, but all history elaborations without a scientific form nicht-wissenschaftsförmigen

Geschichtsverarbeitungen.

Keywords: history didactics; historicaldidactic research methodology; history teaching.

\footnotetext{
${ }^{\star}$ Doutor em Educação - Universidade de São Paulo (USP), Praça Campos da Cunha, 41, ap.3. 05054130 São Paulo - SP - Brasil. oldimar@gmail.com.
} 
No Brasil a Didática da História é freqüentemente entendida como um tema subordinado à área de Educação, sem vínculos com a atuação do pesquisador da área de História. Essa concepção se fundamenta na crença de que o papel da didática é adaptar ao contexto escolar o conhecimento criado pelos historiadores. Porém, diferentemente do que supõe essa concepção, as disciplinas que integram a 'cultura escolar' - culture scolaire - possuem uma autonomia considerável em relação ao 'saber universitário ou erudito' — savoir savant. Segundo André Chervel, o que a escola ensina não é 'a História dos historiadores'. Suas diversas pesquisas sobre a história das disciplinas escolares lhe permitiram afirmar que a cultura escolar não é apenas uma simplificação ou uma vulgarização do saber erudito, da 'História dos historiadores'. O autor demonstra que muitos dos saberes escolares foram criados "pela própria escola, na escola e para a escola" e afirma que um dos objetivos da escola

é a criação das disciplinas escolares, vasto conjunto cultural amplamente original que ela secretou ao longo de decênios ou séculos e que funciona como uma mediação posta a serviço da juventude escolar em sua lenta progressão em direção à cultura da sociedade global. No seu esforço secular de aculturação das jovens gerações, a sociedade entrega-lhes uma linguagem de acesso cuja funcionalidade é, em seu princípio, puramente transitória. Mas essa linguagem adquire imediatamente sua autonomia, tornando-se um objeto cultural em si e, apesar de um certo descrédito que se deve ao fato de sua origem escolar, ela consegue contudo se infiltrar sub-repticiamente na cultura da sociedade global. ${ }^{1}$

A escola é capaz de mais do que criar saberes próprios, ela pode também influenciar o saber erudito, por meio do que Chervel denomina 'efeito Wilamowitz'. A obra de Ésquilo é um dos exemplos considerados por ele para concluir que a relação entre saber erudito e cultura escolar é uma via de mão dupla, e não exclusivamente transposição do primeiro para a segunda. No início da era cristã, seis ou sete séculos depois de Ésquilo escrever dezenas de tragédias, todas elas estavam disponíveis aos leitores. Mas era comum que apenas sete, selecionadas por seu interesse pedagógico particular, fossem utilizadas no ensino. Hoje nos restam apenas essas sete obras; todas as outras desapareceram. Quando lemos Ésquilo atualmente, acreditamos ler um autor grego antigo, mas temos contato apenas com as obras escolhidas para uso dos alunos de uma outra época. Os eruditos que estudam Ésquilo na atualidade o fazem sob o recorte da escola, o que existe hoje não é senão um 'Ésquilo para a 
juventude'. Chervel acrescenta que o mesmo é válido para a obra de Sófocles, de Aristófanes e, parcialmente, para a de Eurípedes.

Outro exemplo do efeito Wilamowitz refere-se ao ensino da ortografia na França. No início do século XIX, ela não integrava o rol de conteúdos do ensino primário francês. Um levantamento realizado em 1829 indicava que apenas $37 \%$ dos professores primários conheciam regras ortográficas. Até aquele momento, a ortografia era vista como uma especialidade profissional dos gráficos, secretárias e escritores públicos — pessoas contratadas para redigir a correspondência de terceiros. Mesmo os professores primários a ignoravam, pois ela ainda não fazia parte da cultura, ou seja, o desconhecimento das regras ortográficas não era critério para classificar uma pessoa como inculta. Foi somente na segunda metade do século XIX, depois de a ortografia passar a integrar os conteúdos da escola primária, que seu conhecimento tornou-se parâmetro de erudição. A importância dada pela escola a esse conteúdo influenciou sua futura valorização pelo saber erudito. ${ }^{2}$

Ao analisar a obra de Chervel, Circe Bittencourt ressalta que

O problema colocado para quem parte do pressuposto da relativa autonomia das matérias escolares diante das ciências de referências decorre da diversidade de disciplinas ou saberes escolares e de como cada uma delas se constituiu. Há indagações, por exemplo, de se as trajetórias das diversas disciplinas escolares seriam semelhantes às da história da gramática nas escolas francesas, conforme estudo de Chervel ... Nesta perspectiva, torna-se imperativa a pesquisa empírica sobre as diferentes disciplinas para a compreensão do processo pelo qual cada uma delas se origina e se instala nos currículos ... Mas é imperativo um posicionamento na investigação quanto à noção de disciplina escolar porque dela depende a fundamentação teórico-metodológica do pesquisador. ${ }^{3}$

Atendendo ao imperativo, indicado por Circe Bittencourt, de posicionar-se quanto à noção de disciplina escolar, as conclusões de Chervel sobre a história das disciplinas escolares são estendidas neste artigo à disciplina escolar História - mesmo que ele jamais a tenha tomado como objeto de suas pesquisas. Isso se justifica pelo fato de que a História escolar tem um caráter autônomo semelhante ao da gramática escolar estudada por Chervel, pois a imensa força política dos usos públicos da História demonstra que a sua forma não-científica - e mais especificamente a História escolar - não se reduz a uma noosphère que apenas filtra o saber a ser ensinado. Se a história das disciplinas escolares francesas demonstra que os professores participam da 
sua criação, podemos considerar o caso brasileiro ainda mais exemplar nesse sentido. Na França, as disciplinas são ensinadas conforme um currículo definido pelo ministério da Educação, que deve ser seguido rigidamente pelos professores. Esse currículo define quantos e quais temas devem ser ensinados a cada série, em que ordem devem ser expostos, quais recortes devem ser feitos e que ênfases precisam ser dadas. O currículo francês define ainda em quais datas tais conteúdos devem ser ensinados - com precisão de dias, e não apenas de anos - e quais são os conceitos principais que os professores precisam transmitir. A atuação destes é limitada ainda pelo trabalho dos inspecteurs, cuja função é também verificar se eles executam o currículo definido pelo Estado. Apesar de toda essa restrição, os professores franceses encontram espaço para participar da criação das disciplinas escolares, como atesta André Chervel em suas pesquisas.

No caso brasileiro, os professores têm mais espaço para a criação das disciplinas escolares, já que não possuímos um currículo. Essa liberdade individual é limitada apenas pelos outros professores da mesma escola, uma vez que o livro didático é selecionado em conjunto, delimitando o currículo. A liberdade também é restringida pelas tradições de ensino de cada escola e, no caso das escolas privadas, pela autoridade do dono ou do coordenador pedagógico. Porém, não há qualquer restrição governamental à elaboração do currículo pelos professores, o que nos leva a crer que tenhamos mais liberdade que os franceses para participar da criação cotidiana das disciplinas escolares.

O conceito de cultura escolar descrito até aqui tangencia um debate brasileiro das décadas de 1980 e 1990 sobre a História escolar: a idéia de ruptura com o 'ensino tradicional' e 'renovação' do ensino dessa disciplina. Esse debate pode ser caracterizado como uma tentativa de ruptura com tradições de ensino de História que remontam à sua origem, na primeira metade do século XIX. Alguns dos autores envolvidos apontavam que, apesar das grandes modificações ocorridas na 'História dos historiadores' após 1930, o ensino de História na escola básica tinha continuado a exercer seu papel original, ocorrendo "poucas mudanças na sala de aula no que se refere à relação com o conhecimento histórico". Para esses autores, as tradições de ensino de História hegemônicas até aquele momento eram pautadas pela exposição cronológica dos feitos políticos dos heróis nacionais, inventoras da "imagem de um único passado, capaz de esclarecer quem eram as autoridades que no presente e no passado eram responsáveis pelo destino da nação". Esse passado único, que "se construiu como memória glorificadora da nação", foi questionado pelos pesquisadores e professores no final do século XX. Tal questionamento visava 
romper com um modelo de ensino de História criado apenas para a "boa sociedade" do século XIX, "constituída por aqueles que eram brancos, livres e proprietários de escravos". No século XX, quando a escola passou a visar o atendimento de todos os futuros cidadãos, e não apenas da "boa sociedade", esse modelo foi questionado. Da "formação do súdito fiel à monarquia", o ensino de História passou à formação do "cidadão consciente e participativo", "em consonância com as questões de seu tempo".

Especialmente na década de 1980, o debate sobre a ruptura com o 'ensino tradicional' e a 'renovação' do ensino da História estava relacionado à intenção de garantir às escolas de primeiro e segundo graus o status de locais produtores de conhecimento. Para muitos dos envolvidos nesse debate, o professor de História da escola básica deveria questionar o papel de 'mero reprodutor' do conhecimento criado pela universidade e configurar-se como 'produtor de conhecimento'. Para isso, seria necessário eliminar a divisão existente na sociedade capitalista entre o trabalho do professor universitário, o 'cientista', e o trabalho do professor da escola básica, o ‘simples técnico' ou 'intermediário da formação de consciências'. Este precisaria se desvencilhar "das determinações implícitas nas ligações do saber e do poder na ordem burguesa" e agir como alguém que é, ao mesmo tempo, representante do 'fazer' e do 'saber.'

O conceito de cultura escolar de André Chervel tangencia esse debate sobre o 'conhecimento histórico escolar' porque define as disciplinas como criações originais do sistema escolar. Na perspectiva da cultura escolar, não faz sentido discutir se professores e alunos têm o direito de 'produzir conhecimento' ou se isso é melhor do que 'reproduzir conhecimento'. Ao dissociar a 'História dos historiadores' da História escolar, Chervel elimina o problema central desse debate. Não está mais em questão se queremos que alunos e professores participem do processo de criação das disciplinas escolares; sua história nos demonstra que eles já fazem isso. Mesmo que os professores não tenham consciência dessa ação criadora e se declarem meros reprodutores da 'História dos historiadores', não é isso que eles são. Mesmo que todos acreditem que a escola ensina 'a História dos historiadores', não é isso que ela faz. Na perspectiva da cultura escolar, não precisamos nos sentir impotentes diante da divisão do trabalho na sociedade capitalista, pois sabemos que essa divisão não impede a escola de desempenhar seu papel de criadora de disciplinas.

Consoante esse conceito de cultura escolar, a Didática da História não pode ser vista como um mero facilitador da aprendizagem. Ela não é o 'facilitador' da transferência do saber erudito à escola, simplesmente porque se reconhece que não há um processo de transferência a ser facilitado. Se a História 
escolar é uma criação da escola, e não uma versão simplificada da 'História dos historiadores', a Didática da História não pode ser uma coleção de métodos - Unterrichtsmethoden - utilizáveis tanto no ensino de História quanto no de outras disciplinas escolares. Quando reconhecemos a autonomia das disciplinas escolares, a Didática da História perde seu caráter prescritivo, deixa de ser um conjunto de procedimentos para melhor transmitir aos alunos a 'História dos historiadores'. A Didática da História também perde o status de 'dramaturgia do ensino' ou 'arte de ensinar' — Lehrkunst —, que ela tinha tal como concebida no século XVII por Jan Comenius.

Para operar com o conceito de cultura escolar de André Chervel faz-se necessário um conceito de Didática da História compatível com suas premissas. Assim é o conceito de Geschichtsdidaktik, utilizado por dezenas de autores alemães como Klaus Bergmann, Jörn Rüsen, Bernd Schönemann e HansJürgen Pandel, entre tantos outros. Para esses autores, a Geschichtsdidaktik não é um mero 'lubrificante' que se passa sobre a História para que ela possa ser ensinada, e também não se resume ao ensino e à aprendizagem da História no contexto escolar. Os autores citados concordam com a afirmação de Henri Moniot: "a didática da história apega-se às operações que transcorrem e aos problemas que se colocam quando se aprende a história, quando se ensina a história: observar, preparar, conduzir ou favorecer essas operações". Porém, discordam de sua afirmação anterior: "É a realidade escolar que constitui o campo da didática da história”. A didática circunscrita pelo conceito de Geschichtsdidaktik pertence à História, é uma parte indissociável dela. A Geschichtsdidaktik abrange mais do que a realidade escolar, ela estuda a "consciência histórica na sociedade”. Essa didática não é apenas mais uma Didaktik der... (didática da...), mas um todo cuja definição numa única palavra — Geschichtsdidaktik — pode não ser casual. ${ }^{6}$

A Geschichtsdidaktik está para a História escolar assim como a Teoria da História - Historik - está para a 'História dos historiadores'. Porém, a Geschichtsdidaktik não é uma reflexão apenas sobre a História escolar, mas sobre todas as 'elaborações da História sem forma científica' - nicht-wissenschaftsförmigen Geschichtsverarbeitungen. A Geschichtsdidaktik é uma auto-reflexão empreendida pelos profissionais que trabalham com essas manifestações culturais da História sem forma científica, definidas pelo conceito de 'cultura histórica’ - Geschichtskultur. Segundo Pandel, a cultura histórica identifica "a forma como uma sociedade lida com seu passado e sua História”. Para Rüsen, a cultura histórica é uma forma específica de experimentar e interpretar o mundo, que descreve e analisa a orientação da prática de vida - menschli- 
chen Lebenspraxis - , a auto-compreensão e a subjetividade dos seres humanos. Nem todas as sociedades possuíram uma cultura histórica: trata-se de um fenômeno da Modernidade, que pressupõe uma História compreendida de forma singular por um coletivo - Kollektivsingular "Geschichte".

Os profissionais que trabalham com a cultura histórica são sobretudo os professores de História, mas também podem ser, entre outros, museólogos, jornalistas, escritores, letristas, roteiristas, cineastas, desenhistas, turismólogos, diretores e autores de teatro que utilizam conteúdos históricos em seus produtos ou obras. Se todos esses profissionais podem ignorar a presença da História escolar em seu trabalho, o inverso não é verdadeiro para os professores de História. Isso porque tudo que tem relação com a cultura histórica - por exemplo, filmes, programas de televisão, romances históricos, peças de teatro, histórias em quadrinhos, pontos turísticos, museus, comemorações de datas históricas, revistas de divulgação científica e outros textos jornalísti$\cos$ - chega às aulas de História pelas mãos dos próprios professores ou por meio de referências trazidas pelos alunos.

A cultura histórica é a forma de expressão da consciência histórica Geschichtsbewußtsein. Jörn Rüsen afirma que a consciência histórica está a um "pequeno passo" da cultura histórica, definida como a "efetiva associação da consciência histórica com a vida de uma sociedade". Para Bernd Schönemann, a consciência histórica e a cultura histórica podem ser definidas sem contradição se forem entendidas, como pela 'Sociologia do Conhecimento' - Wissenssoziologie —, como 'dois lados de uma mesma moeda'. De um lado, a consciência histórica desenvolve-se como um "constructo individual", "durante processos de internalização e de socialização". De outro lado, a cultura histórica, enquanto "constructo coletivo", "desenvolve-se no processo oposto de externalização e de objetivação". Hans-Jürgen Pandel define a consciência histórica como um "modo de elaboração psíquica do saber histórico" - psychischer Verarbeitungsmodus historischen Wissens - formado sobre esse saber mas sem autonomia em relação a ele. A consciência histórica não é o acúmulo de saber histórico, mas o 'modo simbólico' - Sinnbildungsmodus — de elaborar o contingente de informações reunido nesse saber para orientar-se na temporalidade do passado, presente e futuro. Um indivíduo pode ter consciência histórica mesmo sem consciência disso. ${ }^{8}$

É difícil definir consciência histórica com precisão, principalmente se levarmos em conta as diferenças entre os autores francófonos - conscience historique - e germanófonos - Geschichtsbewußtsein. Parte dessas diferenças se deve ao fato de a expressão 'consciência histórica' reunir mais de um con- 
ceito. Um deles define a consciência da disciplina História. Nesse sentido, a consciência histórica é uma consciência disciplinar, uma representação sobre essa disciplina ou sobre a forma como ela organiza simbolicamente o mundo. Nicole Tutiaux-Guillon e Marie-José Mousseau utilizam esse conceito de consciência histórica — conscience historique - ao descrevê-la como uma determinada representação sobre o passado — que supõe "uma ligação entre passado e presente" ou que o "presente serve de referência para compreender o passado" - e sobre conceitos, acontecimentos ou sujeitos específicos desse passado - "a Idade Média, a Revolução Industrial, Hitler”. François Audigier acrescenta que a consciência histórica é um privilégio da Modernidade, que permite tomarmos consciência da relatividade de todas as opiniões. Além disso, ela é a consciência de "ser precedido de maneira insuperável por um mundo que nos dá a possibilidade de ter um projeto, de pensar um futuro" - avenir.

Esse primeiro conceito de consciência histórica se aproxima do que Robert Martineau e Nicole Lautier denominam pensée historienne. Martineau define pensée historienne como um modo de pensar da cultura histórica culture historienne - um domínio específico do pensamento que faz da História mais do que um campo da cultura. Lautier define pensée historienne como uma ação crítica - démarche critique - caracterizada pelas 'operações' de periodização, controle da análise comparativa - contrôle du raisonnement comparatif - , controle do grau de generalização e distinção dos níveis de leitura e escritura - a imagem fixa, o filme, a caricatura, o mapa, as pinturas. Charles Heimberg também se aproxima desse conceito, ao sintetizar "os modos de pensamento específicos da História" em "três atividades fundamentais": a comparação — que abrange duas posturas complementares, a busca de explicações para o presente no passado ou o estudo do passado pelo que ele tem de particular e diferente — , a periodização — que permite estabelecer sucessões e rupturas - e a distinção entre a História e seus usos - por meio da memória ou considerando a presença da História nas obras e nos meios de comunicação. ${ }^{10}$

Um segundo conceito expresso por 'consciência histórica' define o entendimento da inserção social de um indivíduo ou de um grupo na História de sua sociedade. Esse conceito aproxima-se do que a bibliografia sobre Didática da História também chama de memória — mémoire —, de memória coletiva - mémoire collective — ou de identidade — identité. Henri Moniot define 'identidade' como sinônimo de 'consciência' e de 'memória coletiva'. Segundo esse autor, a identidade se constitui das histórias contadas por um 
indivíduo ou por uma comunidade, e que são retocadas, corrigidas, reprimidas, desmentidas e analisadas pelos historiadores. ${ }^{11}$

'Consciência histórica' representa ainda a consciência da temporalidade histórica. Esse conceito define a capacidade humana de situar-se no tempo, não enquanto grandeza física, mas conforme ele foi historicamente concebido desde a Modernidade. Nesse sentido ontogênico, a origem da consciência histórica estaria imersa no processo de aquisição da linguagem. Para falar, os indivíduos aprendem palavras que expressam o tempo — ontem, rápido, freqüentemente etc. - e por meio delas moldam um conceito de tempo próprio de sua cultura. Esse conceito de tempo não é 'lógico', mas 'histórico': é o tempo "socialmente produzido", "das inovações técnicas, da dinâmica das organizações, da formação de normas”. O significado da palavra 'rápido', por exemplo, pode variar de uma cultura para outra. ${ }^{12}$

O quarto conceito de consciência histórica, proposto por Jörn Rüsen, a define como "fundamento de todo conhecimento histórico". Para Rüsen, todas as formas de conhecimento histórico, inclusive a ciência da História Geschichtswissenschaft —, são "um modo particular de um processo genérico e elementar do pensamento humano". Isso lhe permite definir a consciência histórica como "fundamento da ciência da história" e embasar esta ciência num processo externo a qualquer "concepção particular da história, vinculada a tal ou qual cultura”. Poderíamos ainda pensar num quinto conceito de consciência histórica que, de acordo com a definição hegeliana, desfizesse a sinédoque contida na palavra 'história', que confunde os acontecimentos — res gestas e a sua narrativa - historiam rerum gestarum. Essa diferenciação poderia ser efetuada pelos conceitos de Geschichtsbewußtsein e Historienbewußtsein, que seriam igualmente traduzidos por 'consciência histórica' em línguas que não possuem substantivos diferentes para a história enquanto acontecimento e para a história enquanto narrativa - como o português, o inglês e o francês. ${ }^{13}$

Em suma, a expressão 'consciência histórica' pode definir o pensar segundo conceitos e métodos históricos - pelo desenvolvimento de uma representação da disciplina História e da forma de pensamento disciplinar que lhe é subjacente - , o entender-se parte de uma história, o situar-se no tempo, o fundamento do conhecimento histórico e talvez a consciência de que há uma diferença entre os acontecimentos e sua narrativa. Independentemente de qual ou quais definições se utilizam, todas elas se expressam na cultura histórica, que por sua vez é estudada pela Geschichtsdidaktik. Há coerência na utilização de mais de um desses conceitos de consciência histórica, ou na utilização de vários como se fossem um só, desde que haja compatibilidade en- 
tre eles. Por exemplo, as três primeiras definições podem ser complementares, e o mesmo ocorre com a terceira e quarta. Porém a segunda e quarta definições são inconciliáveis.

Tanto Wolfgang Hasberg quanto Bernd Schönemann dividem a Geschichtsdidaktik em três áreas de trabalho principais: teoria, empiria e pragmática. $\mathrm{Na}$ área da teoria, ela atua como uma instância de reflexão que visa esclarecer seu próprio objeto de pesquisa. $\mathrm{Na}$ área da empiria, funciona como uma 'ciência experimental' - Erfahrungswissenschaft - que examina a cultura histórica ou a consciência histórica de uma sociedade sem a intenção de interferir nelas. A Geschichtsdidaktiké definida como uma ciência experimental somente porque atua em campo, mesmo que aí não realize propriamente experimentos — e sim observações. Já na área da pragmática, ela pretende influenciar as escolas e todos os outros locais de expressão da cultura histórica, como museus, arquivos, imprensa, televisão etc. Nessa área portanto ela faz as vezes de uma 'ciência-ação' - Handlungswissenschaft — que estuda a consciência histórica com o objetivo principal de interferir nela. A pesquisa pautada no conceito de Geschichtsdidaktik é uma 'pesquisa didático-histórica' - geschichtsdidaktische Forschung. Uma pesquisa que se restringe ao que Wolfgang Hasberg e Bernd Schönemann denominam 'área da empiria' pode ser chamada de 'pesquisa de campo didático-histórica' — geschichtsdidaktische Feldforschung. ${ }^{14}$

Para Jörn Rüsen, "o cotidiano do historiador constitui a base natural da Teoria da História” (Rüsen, 2001, p.25). De acordo com a analogia já sugerida neste artigo entre Historik e Geschichtsdidaktik, a base desta última seria o cotidiano da criação da cultura histórica, que em muitos casos é o cotidiano do professor de História. Portanto, o lugar da pesquisa de campo didáticohistórica é o cotidiano das aulas de História ou de qualquer espaço de expressão da cultura ou da consciência históricas. Ao focar o cotidiano, ela adota procedimentos caros tanto à antropologia quanto à etnografia da escolarização, mas ainda que possa se apoiar em metodologias oriundas dessas duas áreas - e de muitas outras áreas, como a psicologia e a ergonomia —, ela não é uma pesquisa etnográfica, ergonômica ou mesmo uma investigação sobre o que se convencionou chamar de Didática Geral. A pesquisa didático-histórica não é o discurso de um antropólogo sobre um contexto familiar que ele precisa estranhar ou a crítica de um pedagogo à forma de organização das aulas do ponto de vista das ciências da educação. Ela é um discurso de um profissional da cultura histórica sobre essa mesma cultura, que tem um grande 
impacto, pois limita o seu diálogo com outras disciplinas em função da coerência entre elas e a cultura histórica.

Por exemplo, uma pesquisa de campo didático-histórica jamais ignora ou mesmo relega a segundo plano os conteúdos tratados numa aula. Quando um pesquisador das ciências da educação enfoca a organização das aulas e abstrai os conteúdos nelas tratados, está agindo de acordo com princípios metodológicos que são coerentes com seu objeto, mas que seriam incoerentes numa pesquisa didático-histórica. A cultura histórica sempre se apresenta tanto na forma como no conteúdo da aula. Ainda que possa espelhar-se em pesquisas educacionais, uma pesquisa de campo didático-histórica sempre se submete ao pressuposto de entender forma e conteúdo da aula como um todo inseparável. Mais do que isso, ela sempre entende o que ocorre na sala de aula como apenas uma parte de um todo mais amplo, que engloba todas as elaborações da História sem forma científica. O que ocorre na sala de aula é só uma parte da cultura histórica, aquela chamada de História escolar, que mantém relações indissociáveis com outras expressões dessa cultura — livros didáticos, filmes, programas de televisão, sites da internet etc. —, mesmo que tais relações não sejam sempre visíveis aos olhos dos atores de campo ou do pesquisador. Essas relações indissociáveis típicas da cultura histórica impedem o pesquisador de tratá-la como um texto - culture-as-text - , pois ela não é algo separado de seus autores e contexto histórico.

Ainda quanto à coerência metodológica, esse tipo de pesquisa não se limita ao que ficou conhecido como 'antropologia de varanda', em referência aos etnógrafos que coletavam informações dos nativos nas varandas das casas dos governantes coloniais. Apesar de deixarem seus gabinetes para ir a campo, o que já representava uma mudança significativa para a antropologia, os antropólogos de varanda apenas entrevistavam os que se dirigiam até eles. A pesquisa de campo didático-histórica não se dirige até a escola para entrevistar professores e alunos, mas para conviver e experienciar com eles.

O diálogo da pesquisa de campo didático-histórica com outras disciplinas também é limitado pela coerência entre elas e os métodos e conceitos históricos. Ainda que possa se beneficiar das reflexões dos antropólogos sobre sua atuação em campo, tal tipo de investigação não se concentra nas comparações com elementos externos à sua própria cultura - o que seria uma prática coerente com a pesquisa antropológica. Diferentemente desta última, a pesquisa de campo didático-histórica não é uma ponte entre dois mundos culturais; ela é uma auto-reflexão sobre a cultura histórica. O estabelecimento de paralelos entre culturas distintas não faz parte da reflexão didático-his- 
tórica. As reflexões dos antropólogos sobre as pesquisas de campo podem lhe ensinar muito, mas somente nos aspectos que guardam coerência com a História. ${ }^{15}$

Porém, a pesquisa de campo didático-histórica não tem compromissos rígidos com alguns conceitos e métodos que são canônicos para essas outras disciplinas. Por exemplo, o estranhamento do familiar, que é fundamental para a pesquisa antropológica, não é uma condição de êxito da primeira. Entretanto, um outro problema surgiu para os antropólogos desde que deixaram de se dedicar exclusivamente às culturas que lhes parecem exóticas e passaram a observar também as culturas urbanas nas quais eles próprios estão inseridos. Essa mudança paradigmática exigiu-lhes um esforço de estranhamento, necessário para não criar uma descrição redundante de sua própria cultura. O problema do estranhamento transferiu-se posteriormente para a etnografia da escolarização, pois como seu pesquisador já foi aluno e muitas vezes também já foi ou ainda é professor, tudo que ele observa na sala de aula pode lhe parecer extremamente familiar. Porém, ainda que o estranhamento possa ser um processo importante para a pesquisa de campo didático-histórica - tanto quanto seu inverso, a empatia com o estranho —, o estudo da cultura histórica pode descrever situações familiares sem obrigatoriamente estranhá-las. A descrição do que é familiar já é suficiente, enquanto autoreflexão profissional, se sua associação aos conceitos históricos e didáticohistóricos permitir compreendê-lo melhor.

O estranhamento não é uma condição de êxito de pesquisas de campo didático-históricas porque as diferentes experiências e vivências profissionais do pesquisador na área da cultura histórica não são obstáculos à análise do contexto de campo. ${ }^{16}$ Pelo contrário, essas experiências e vivências são um elemento indispensável à realização da pesquisa enquanto auto-reflexão. A familiaridade do pesquisador com a cultura histórica não é um problema, mas a condição sine qua non da pesquisa didático-histórica. É somente o confronto das experiências e vivências do pesquisador com as do contexto de campo que possibilita a auto-reflexão sobre a cultura histórica. As experiências e vivências do pesquisador não são portanto uma parte da sua subjetividade que precisaria ser eliminada. Em vez de eliminá-la, ele precisa explicitála aos atores de campo e adquirir consciência dela, com o intuito de administrá-la.

O pesquisador didático-histórico busca uma relação de empatia com os atores de campo, analisando suas representações a partir da compreensão de seus pontos de vista. Para isso, é necessário estabelecer certa diferença entre 
observação e interpretação. É necessário dizer 'certa diferença', pois observação e interpretação são parte de um mesmo processo. ${ }^{17}$ Observamos o mundo por meio de sentidos culturalmente enformados, dos quais é impossível nos isentarmos. Procurar distinguir observação de interpretação não significa crer na objetividade científica absoluta, mas buscar constantemente a maior proximidade possível do objeto, mesmo que, por definição, ele não seja alcançável. Significa também realizar uma observação mais refletida do que espontânea, para tanto focada nos gestos, não nos sentidos. Para dar um exemplo concreto, a tentativa de separar observação de interpretação ocorre quando o pesquisador registra que o professor afirmou que os populistas eram 'demagogos' - e ao final da aula pergunta para o professor o que exatamente essa palavra significa para ele naquele contexto - em vez de registrar que o professor criticou o populismo.

O objetivo de tal tentativa de separação é garantir que a retomada do material elaborado e coletado pelo pesquisador em campo permita atribuir aos gestos um sentido diferente daquele que seria atribuído no 'calor' do campo. Se o pesquisador registra que o professor criticou o populismo, não há a oportunidade de reinterpretar sua declaração de uma forma mais refletida. Buscar separar observação de interpretação significa evitar juízos de valor muito rígidos em campo, para conferir um papel importante à reflexão efetuada fora dele. Em outros casos, mais complexos do que esse exemplo, a separação é impossível. Então, observação e interpretação fundem-se em campo de forma indistinguível. Por isso, o esforço para distinguir observação e interpretação não garante nenhuma objetividade à interpretação do pesquisador, mas expressa sua responsabilidade de aproximar-se constantemente de seu objeto. Tal responsabilidade é necessária para evitar que a pesquisa de campo didático-histórica fique refém da autoridade do pesquisador e permitir que assuma como critérios de validade a apresentação de 'provas' e a adequação de suas afirmações ao real. ${ }^{18}$

Até aqui este artigo buscou definir a Didática da História como uma disciplina que tem por objeto de estudo todas as elaborações da História sem forma científica. Essa definição fundamenta-se sobretudo na bibliografia alemã contemporânea sobre a Geschichtsdidaktik, surgida em oposição às definições da Didática como arte de ensinar — Lehrkunst — ou como coleção de métodos indiferentemente utilizáveis no ensino de qualquer disciplina escolar - Unterrichtsmethoden. De acordo com a definição de Didática da História exposta neste artigo, essa disciplina não estuda apenas o ensino e a aprendizagem da História escolar, mas todas as expressões da cultura e da consciência 
históricas que circulam dentro e fora da escola. Ainda que a Didática da História tenha aqui fortes relações com a História escolar, dada a imensa importância social desta, as pesquisas didático-históricas não se limitam ao contexto institucional da educação básica nem propõem compreendê-lo isolado da cultura e da consciência históricas externas a ele. Como escola e sociedade se influenciam mutuamente, de um ponto de vista didático-histórico não faz sentido diferenciar a História escolar das outras elaborações da História sem forma científica. Não interessa à Didática da História estudar o contexto escolar apenas para compreendê-lo, mas como campo de pesquisa para a compreensão da cultura e da consciência históricas na sociedade como um todo. Se a História escolar não é o objeto exclusivo da Didática da História conforme definida neste artigo, essa área de estudo não é pedagógica, mas histórica, ao contrário das representações mais comuns sobre ela no Brasil. De acordo com a presente exposição, não cabe pensar em relações entre a didática e a História, como duas disciplinas separadas que se uniriam para que a primeira tornasse a segunda mais palatável, no intuito de torná-la acessível ao público leigo. Assim, não existem relações entre a didática e a História porque a Didática da História é uma disciplina parcial da História, mais especificamente, uma que se utiliza de referencial teórico desta para compreender suas elaborações sem forma científica.

Com base na definição de Didática da História sintetizada no parágrafo anterior, podemos definir a pesquisa de campo didático-histórica como situada no cotidiano de qualquer espaço de expressão da cultura ou da consciência históricas. Esse espaço não se restringe às aulas de História, mas inclui também os espaços de atuação de museólogos, jornalistas, escritores, letristas, roteiristas, cineastas, desenhistas, turismólogos, diretores e autores de teatro que utilizam conteúdos históricos em seus produtos ou obras. Ainda que a pesquisa de campo didático-histórica possa ser realizada no cotidiano escolar, ela não é estritamente uma pesquisa educacional, pois suas conclusões não se restringem a esse contexto. A pesquisa de campo didático-histórica pode ser realizada no cotidiano escolar, mas não é apenas sobre o cotidiano escolar, pois suas conclusões sempre dizem respeito à cultura e à consciência históricas que se expressam para além dele. O que diferencia a pesquisa didático-histórica da pesquisa pedagógica sobre ensino de História é o fato de que esta última pode restringir suas conclusões à História escolar, enquanto a primeira, mesmo quando estuda o cotidiano escolar, visa compreender a cultura e a consciência históricas de uma forma mais ampla. Ainda que um pesquisador em Didática da História se apóie em metodologias oriundas da 
antropologia ou da etnografia da escolarização, seu trabalho estará sempre subordinado à Teoria da História.

\section{NOTAS}

${ }^{1}$ Cf. CHERVEL, André. História das disciplina escolares: reflexões sobre um campo de pesquisa. Teoria \& Educação. Porto Alegre: Pannonica, n.2, p.117-229, 1990.

${ }^{2} \mathrm{O}$ 'efeito Wilamowitz' é uma referência ao filólogo alemão Ulrich von Wilamowitz-Möllendorff, o primeiro autor a sugerir, em 1889, a influência da escola sobre o saber erudito, confirmada em pesquisas mais recentes. Cf. CHERVEL, André. La culture scolaire: une approche historique. Paris: Belin, 1998, p.183-184, 187-188, 234 (nota 5).

${ }^{3}$ Cf. BITTENCOURT, Circe Maria Fernandes. Disciplinas escolares: história e pesquisa. In: OLIVEIRA, Marcus Aurelio Taborda de; RANZI, Serlei Maria Fischer. História das disciplinas escolares no Brasil: contribuições para o debate. Bragança Paulista: Edusf, 2003. p.28-29.

${ }^{4}$ Cf. CORDEIRO, Jaime Francisco Parreira. A história no centro do debate: as propostas de renovação do ensino de História nas décadas de 1970 e 1980. Araraquara: Laboratório Editorial Unesp, 2000; BITTENCOURT, Circe Maria Fernandes. Pátria, civilização e trabalho: o ensino de História nas escolas paulistas (1917-1939). São Paulo: Loyola, 1990, p.199-200; SIMAN, Lana Mara de Castro. Pintando o descobrimento: o ensino de História e o imaginário de adolescentes. In: ; FONSECA, Thais Nivia de Lima e (Org.) Inaugurando a História e construindo a nação: discursos e imagens no ensino de História. Belo Horizonte: Autêntica, 2001, p.149-170; MATTOS, Selma Rinaldi de. Lições de Macedo: uma pedagogia do súdito-cidadão no Império do Brasil. In: MATTOS, Ilmar Rohloff de (Org.) Histórias do ensino da História no Brasil. Rio de Janeiro: Access, 1998, p.31-44; FONSECA, Thais Nivia de Lima e. História \& Ensino de História. Belo Horizonte: Autêntica, 2003, p.88.

${ }^{5}$ Cf. ABUD, Kátia Maria. Conhecimento histórico e ensino de História: a produção de conhecimento histórico escolar. Encontros com a História. XIV Encontro Regional de História, Sujeitos na História: práticas e representações, 8-11 set. 1998. Anpuh-SP/PUC-SP. Bauru: Edusc, 2001, n.2, p.127-141; CRUZ, Heloísa de Faria. Ensino de História, da reprodução à produção de conhecimento. In: SILVA, Marcos Antônio da (Org.) Repensando a História. Rio de Janeiro: Marco Zero, 1984, p.25-29; MARSON, Adalberto. Reflexões sobre o procedimento histórico. In: SILVA, 1984, p.37-64. A discussão sobre a "produção do conhecimento histórico escolar", que visava superar as tradições de ensino em questão, atingiu até mesmo os documentos curriculares da época, como as Propostas Curriculares publicadas em 1989 e 1992 pela Coordenadoria de Estudos e Normas Pedagógicas (Cenp) da Secretaria de Estado da Educação de São Paulo e os Parâmetros Curriculares Nacionais publicados em 1997.

${ }^{6}$ Cf. BERGMANN, Klaus; FRÖLICH, Klaus; KUHN, Annette; RÜSEN, Jörn; SCHNEIDER, Gerhard (Org.) Handbuch der Geschichtsdidaktik. Seelze/Velber: Kallmeyer, 1997; MONIOT, 
Henri. Didática da história. In: BURGUIÈRE, André. Dicionário das ciências históricas. Rio de Janeiro: Imago, 1993, p.225-228; SCHÖNEMANN, Bernd. Geschichtsdidaktik. In: MAYER, Ulrich; PANDEL, Hans-Jürgen; SCHNEIDER, Gerhard; SCHÖNEMANN, Bernd (Org.) Wörterbuch Geschichtsdidaktik. Schwalbach: Wochenschau, 2006, p.72-73.

${ }^{7}$ Cf. PANDEL, Hans-Jürgen. Geschichtskultur. In: MAYER, Ulrich et al. (Org.) Wörterbuch Geschichtsdidaktik. Schwalbach: Wochenschau, 2006, p.74-75; RÜSEN, Jörn. Geschichtskultur. In: BERGMANN, Klaus et al. (Org.) Handbuch der Geschichtsdidaktik. Seelze/Velber: Kallmeyer, 1997, p.38-41. Ainda que alguns historiadores recusem o rótulo de 'ciência' (Wissenschaft) para sua disciplina e se acreditem apenas autores de um gênero literário, utilizamos a expressão 'História dos historiadores' como sinônimo do conceito alemão de 'Ciência da História' (Geschichtswissenschaft). A distinção entre a 'História dos historiadores' como científica e a cultura histórica como não-científica obedece aqui a um critério puramente institucional. Os historiadores falam de um lugar que tem status e responsabilidades científicas - mesmo que recusados por eles -; todos os demais não têm essa prerrogativa.

${ }^{8}$ Cf. RÜSEN, Jörn. Was ist Geschichtskultur? Überlegungen zu einen neuen Art, über Geschichte nachzudenken. In: FÜßMANN, Klaus et al. (Org.) Historische Faszination: Geschichtskultur heute. Köln: Böhlau, 1994, p.3-26; SCHÖNEMANN, Bernd. Geschichtskultur als Forschungskonzept der Geschichtsdidaktik. Zeitschrift für Geschichtsdidaktik. Schwalbach: Wochenschau, p.78-86, 2002; PANDEL, Hans-Jürgen. Geschichtsbewusstsein. In: MAYER, Ulrich et al. (Org.) Wörterbuch Geschichtsdidaktik. Schwalbach: Wochenschau, 2006, p. 69-70.

${ }^{9}$ Sobre o conceito de consciência disciplinar (conscience disciplinaire) enquanto "representação de uma disciplina", cf. REUTER, Yves. La represéntation de la discipline ou la conscience disciplinaire. La Lettre de la D.F.L.M.. AIRDF, v.1, n.32, p.18-22, 2003. Cf. TUTIAUXGUILLON, Nicole; MOUSSEAU Marie-José. Les jeunes et l'histoire: identités, valeurs, conscience historique. Paris: INRP, 1998, p.101-102; AUDIGIER, François. Les jeunes, la conscience historique et l'enseignement de l'histoire. In: TUTIAUX-GUILLON, Nicole; MOUSSEAU, Marie-José. Les jeunes et l'histoire: identités, valeurs, conscience historique. Paris: INRP, 1998, p.127-133.

${ }^{10}$ Cf. MARTINEAU, Robert. L'histoire à l'école, matière à penser... Paris: L'Harmattan, 1999, p.109-140; LAUTIER, Nicole. Enseigner l'histoire au lycée. Paris: Armand Colin, 1997, p.124128; HEIMBERG, Charles. L'Histoire à l'école: modes de pensée et regard sur le monde. Issy-les-Moulineaux: ESF, 2002, p.41.

${ }^{11}$ Cf. LAVILLE, Christian. Pour une éducation historique critique, qu'attendre du courant de la conscience historique? In: TUTIAUX-GUILLON, Nicole; NOURRISSON, Didier (Org.) Identités, mémoires, conscience historique. Saint-Étienne: Publications de l'Université de Saint-Étienne, 2003, p.13-25; MONIOT, Henri. Didactique de l'Histoire. Paris: Nathan, 1993, p.77. Luis Fernando Cerri utiliza conceito semelhante de consciência histórica, ao defini-la como os "significados que são construídos em (e/ou por) cada grupo humano sobre si próprio, caracterizando-se no tempo e no espaço”. Cf. CERRI, Luis Fernando. En- 
sino de História e Nação na Propaganda do 'Milagre Econômico'. Revista Brasileira de História, São Paulo: Anpuh, v.22, n.43, p.195-224, 2002.

${ }^{12}$ Cf. KLOSE, Dagmar. Geschichtsbewußtsein — Ontogenese. In: BERGMANN, Klaus et al. (Org.) Handbuch der Geschichtsdidaktik. Seelze/Velber: Kallmeyer, 1997, p.51-56; LEPETIT, Bernard. Le présent de l'histoire. In: LEPETIT, Bernard (Org.) Les formes de l'expérience: une autre histoire sociale. Paris: Albin Michel, 1995, p.273-298. Maria Auxiliadora Schmidt e Tânia Braga Garcia utilizam conceito semelhante de consciência histórica, ao afirmarem que ela "dá à vida uma 'concepção do curso do tempo', trata do passado como experiência e 'revela o tecido da mudança temporal no qual estão amarradas as nossas vidas, bem como as experiências futuras para as quais se dirigem as mudanças'. Essa concepção molda os valores morais a um 'corpo temporal', transformando esses valores em 'totalidades temporais', isto é, recupera a historicidade dos valores e a possibilidade dos sujeitos problematizarem a si próprios e procurarem respostas nas relações entre passado/presente/futuro". Cf. SCHMIDT, Maria Auxiliadora Moreira dos Santos; GARCIA, Tânia Maria F. Braga Garcia. A formação da consciência histórica de alunos e professores e o cotidiano em aulas de história. Cadernos Cedes, São Paulo: Cedes, v.25, n.67, p.297-308, 2005.

${ }^{13}$ Cf. RÜSEN, Jörn. Razão Histórica: Teoria da História — os fundamentos da ciência histórica. Brasília: Ed. UnB, 2001, p.56. Sobre a diferença entre res gestas e historiam rerum gestarum, cf. HEGEL, Georg Wilhelm Friedrich. Vorlesungen über die Philosophie der Geschichte. Werke, Band 12. Frankfurt: Suhrkamp, 1973, p.65. Na língua alemã atual, história enquanto acontecimento é Geschichte e história enquanto narrativa é Historie, daí a tentativa de expressar diferentemente os dois conceitos de consciência histórica propostos. A língua inglesa diferencia history de story, mas não diferencia um acontecimento de sua narrativa, reforçando a indiferenciação do ponto de vista leigo ao atribuir um caráter de ficção para story e de suposta verdade para history. Apesar de não possuírem substantivos diferentes para história enquanto acontecimento e história enquanto narrativa, as línguas inglesa e francesa possuem respectivamente os adjetivos historic e historique - relativos a res gestae - e os adjetivos historical e historienne — relativos a historia rerum gestarum -, o que ameniza a indiferenciação. A palavra historienne ainda consta dos dicionários franceses apenas como substantivo, mas é utilizada como adjetivo há algumas décadas na bibliografia sobre Didática da História.

${ }^{14}$ Cf. HASBERG, Wolfgang. Methoden geschichtsdidaktischer Forschung: Problemanzeige zur Methodologie einer Wissenschaftsdisziplin. Zeitschrift für Geschichtsdidaktik. Schwalbach: Wochenschau, p.59-77, 2002; SCHÖNEMANN, Bernd. Geschichtsdidaktik in MAYER, Ulrich et al. (Org.) Wörterbuch Geschichtsdidaktik. Schwalbach: Wochenschau, 2006, p.72-73.

${ }^{15} \mathrm{O}$ estabelecimento de paralelos entre culturas distintas, prática comum entre os antropólogos, tem um de seus exemplos clássicos na relação sugerida por Clifford Geertz entre a briga de galos balinesa e a arte européia. De um ponto de vista histórico, usar conceitos artísticos estritamente europeus para descrever uma briga de galos balinesa é um grave anatopismo, incoerente com a pesquisa histórica. Sobre essa relação, cf. GEERTZ, Clifford. A interpretação das culturas. Rio de Janeiro: Zahar, 1978, p.318. Sobre críticas a essa rela- 
ção, cf. SCHNEIDER, Mark A. Culture as a text? In: Culture and Enchantment. Chicago: University of Chicago Press, 1993, p.55; FREITAS, Renan Springer de; BATITUCCI, Eduardo Cerqueira. A falácia da interpretação da cultura como texto. Lua Nova, São Paulo: Cedec, n.40/41, p.267-288, 1997.

${ }^{16}$ Os conceitos de experiência - Erfahrung - e vivência — Erlebnis — são utilizados aqui conforme a tradição da filosofia alemã, que define a experiência como o começo de todo o conhecimento e a vivência como a mera passagem do tempo num dado lugar. O substantivo Erfahrung é constituído pelo verbo fahren (viajar), que lhe dá o sentido de "partir em viagem para explorar ou ficar a conhecer algo". Cf. INWOOD, Michael. Dicionário Hegel. Rio de Janeiro: Jorge Zahar, 1997, p.130-132. Por isso, um professor com quarenta anos de "experiência profissional" — no sentido vulgar dessa expressão — tem quarenta anos de vivência, mas pode não ter experiência — Erfahrung — alguma.

${ }^{17}$ Norwood Russell Hanson considera que “observações e interpretações são inseparáveis - não apenas no sentido de que nunca se manifestam separadamente, mas no sentido de que é inconcebível manifestar-se qualquer das partes sem a outra". Cf. RUSSELL HANSON, Norwood. Observação e interpretação. In: MORGENBESSER, Sidney (Org.) Filosofia da ciência. São Paulo: Cultrix, 1975, p.127.

${ }^{18}$ Como escreveu Paul Willis, as "teorias devem ser julgadas, em última instância, pela adequação que representam em relação à compreensão do fenômeno que elas pretendem explicar — não em relação a si mesmas". Cf. WILLIS, Paul. Aprendendo a ser trabalhador: escola, resistência e reprodução social. Porto Alegre: Artes Médicas, 1991, p.236. Sobre o conceito de 'prova', cf. GINZBURG, Carlo. Relações de força: História, retórica, prova. São Paulo: Companhia das Letras, 2002, p.11-18.

Artigo recebido em janeiro de 2008. Aprovado em abril de 2008. 